DOSSIÊ: CORPOS, TRAJETÓRIAS E VALORES: PERSPECTIVAS DE GÊNERO, FAMÍLIAS E REPRODUÇÃO SOCIAL EM CONTEXTOS AFRICANOS

\title{
Seguindo as tramas da beleza: cabelos na centralidade estético-corporal de Maputo*
}

\author{
Denise Ferreira da Costa Cruz**
}

\begin{abstract}
Resumo
$\mathrm{O}$ artigo versa sobre a centralidade da cabeça para investimentos estético-corporais no contexto estudado e busca compreender os significados destas práticas a partir de entendimentos locais sobre corpo.
\end{abstract}

Palavras-chave: Corpo, Beleza, Cabelo, Feminino.

* Recebido para publicação em 12 de maio de 2015, aceito em 24 de agosto de 2015.

** Doutoranda do Programa de Pós-Graduação em Antropologia Social da UnB, Brasília, DF, Brasil. deniseklaxon@gmail.com 
136 Seguindo as tramas da beleza

Following the Warps of Beauty: Hair in the Center of Body Aesthetics in Maputo

\begin{abstract}
This paper focuses on the centrality of hair in body aesthetics investments in the studied context. Since hair has a major role in the aesthetic building of the body, the article seeks to understand the meanings of these practices based on local understandings of the body.
\end{abstract}

Key Words: Body, Beauty, Hair, Feminity. 


\section{Introdução}

Gestos bastante simples e cotidianos mobilizaram este trabalho. Logo nos primeiros dias de estadia na cidade de Maputo, por ocasião da minha pesquisa de mestrado em 2011, fascinavam-me algumas imagens que eu perseguia, buscando me familiarizar com aquele espaço. Não era raro, por exemplo, ver nos passeios da Avenida Guerra Popular ${ }^{1}$, localizada na parte baixa da cidade, uma sequência de três mulheres envoltas em capulanas $^{2}$, em que uma delas estava sentada no chão, forrado também por uma capulana, sendo trançada por uma outra que se mantinha sentada em uma cadeira e que tinha seus cabelos trabalhados por uma terceira, a qual se posicionava de pé. Imagens como essa se avolumavam quando passei a frequentar outros bairros $e$ a conviver com algumas pessoas no universo doméstico.

Entre vielas e casas do bairro Zona Verde ${ }^{3}$, num sábado à tarde, havia quatro ou cinco mulheres trançando uma que se mantinha sentada na cadeira, segurando mechas de cabelos sintéticos que lhe seriam aplicados, ou plantados como se diz na linguagem local. Acompanhando visualmente essa dinâmica, eu notava que o número de mulheres que a trançavam se alterava, mas pelo menos uma continuava o trabalho que certamente

\footnotetext{
1 A Avenida Guerra Popular era bastante frequentada por mim e pelas amigas que fiz em Maputo. Lá é possível encontrar uma infinidade de produtos como sapatos, roupas usadas, roupas indianas, capulanas, cabelos, eletrônicos, etc.

2 Tecidos de algodão produzidos industrialmente fora de Moçambique e que estão presentes na vestimenta de muitas mulheres moçambicanas. Descrito por Sofia Vilarinho como: "Um pano rectangular geralmente de $150 \mathrm{~cm}$ por $110 \mathrm{~cm}$, estampado industrialmente em toda a sua superfície e que se diferencia de país para país pelos motivos africanos de cores contrastantes, formas antropomórficas, zoomórficas ou abstractas e padrões geométricos e figurativos variáveis que ilustram a cultura, a tradição, a contemporaneidade, os rituais, as ideias, a emoção, o silêncio, a revolta, a luta, a paixão" (Vilarinho, 2011). No capítulo 3, o uso desse tecido pelas mulheres que conheci será descrito.
}

3 O Bairro Zona Verde é denominado por essas mulheres como bairro de caniço. 
ocuparia algumas horas daquela tarde. A conversa que embalava o trabalho de pentear variava entre comentários sobre parentes, comida, compras de roupa ou comentários sobre a novela brasileira que estava no ar. Essa mesma imagem, vista no quintal de uma casa, pode ser transferida para um espaço profissional, como um salão de beleza no Mercado Janet, que se localiza em uma rua paralela à Mao Tsé-Tung. ${ }^{4}$

As imagens pinceladas acima sobre espaços e corpos distintos se alinhavam ao tema que será trabalhado neste artigo: a simbolização de um corpo feminino e sua relação com as técnicas, gestos e adornos necessários para sua construção - no caso, das mulheres com quem me relacionei em Maputo. $\mathrm{O}$ artigo versará sobre a centralidade da cabeça para investimentos estéticocorporais no contexto estudado e buscará compreender os significados dessas práticas a partir de entendimentos locais sobre corpo. Os cabelos, por sua vez, apresentam uma centralidade na fabricação estética desse corpo. Cabelos simbolizam a pessoa porque, junto com o rosto, ele é o maior fator de identificação de uma pessoa para a outra (Malysse, 2002:4-5). Vê-se em Maputo, entre as mulheres "negras" ${ }^{\circ}$ que conheci, uma verdadeira celebração em torno dos cabelos. Muito tempo é dedicado a eles; muito dinheiro é gasto para adorná-los; uma verdadeira estética da cabeça é vivenciada por essas mulheres. São esses os pontos que buscarei trabalhar neste texto mostrando o quão central é essa parte do corpo para as mulheres "negras" que conheci.

\footnotetext{
4 Avenida localizada na parte alta da cidade. Nela estão localizados bares, restaurantes e hotéis, sendo uma área apreciada por turistas.

5 A palavra negra vem entre aspas a fim de ponderar uma essência nesse pertencimento étnico-racial. As mulheres que conheci se autorreferenciavam como negras, no entanto, quero me afastar da ideia de raça como algo biológico ou essencialista, considerando ser esse pertencimento algo relacional $e$ contextualizado.
} 


\section{Cabeça como suporte para investimentos estéticos}

Os cabelos das mulheres que passavam pelas ruas de Maputo chamavam-me a atenção de maneira especial. A variedade de penteados que observei nessa cidade confrontava-se a imagens de cidades brasileiras por onde circulo - Belo Horizonte e Brasília, sobretudo - onde esses não aparecem, a meu ver, de maneira tão diversa e exuberante. Os cabelos foram objeto de admiração da minha parte, permitiram-me entender algumas nuances sobre a noção local de pessoa, foram mediadores de relações e de entendimentos sobre corpos alheios.

Os cuidados com os cabelos assumiram, entre as moçambicanas que conheci, um gesto que a um só tempo desloca nosso olhar e o foco da análise do cabelo para a cabeça, conformando o que passei a chamar de "estética da cabeça". Tal formulação assumiu sentido à medida que eu via a recorrência do gesto do dedo indicador apontando insistentemente para o topo da cabeça, quando lhes perguntava algo relacionado ao tema da beleza. Tal gesto surgia mesmo espontaneamente, quando elas afirmavam ser essa a parte do corpo em que se localiza a beleza feminina, região para a qual lança-se o primeiro olhar sobre a pessoa. Uma cabeleireira que tem seu salão no Mercado Janet devolveu-me uma pergunta após ter se cansado das minhas:

- Onde fica a beleza da mulher?

- Não sei... - respondi.

- Na cabeça! Ou não é? Se a mulher não tem a cabeça bonita, o que ela tem?

Da mesma forma, outras mulheres reagiam e elaboravam argumentos parecidos:

- O primeiro lugar para onde uma pessoa olha é para a cabeça. [aponta o dedo indicador para o topo da cabeça] Se a cabeça está bonita, então tudo está bonito. Não interessa o que vai no corpo [aponta para o resto do corpo referindo-se à vestimenta]. 
Esse gesto aparentemente banal simboliza um deslocamento sutil, mas nem por isso menor, do locus corporal privilegiado para empreendimentos estéticos, do cabelo para a cabeça. Ele apresenta sua especificidade, o que pude perceber quando, de volta ao Brasil, em conversas desinteressadas com amigos, perguntava onde estaria localizada a beleza para nós. Em geral indicavam-me o rosto, em um gesto circular com as mãos, algumas vezes mencionando os glúteos. Não houve quem apontasse o dedo indicador para o topo da cabeça, embora o cuidado com os cabelos seja algo compartilhado e os salóes de beleza sejam muito importantes $e$ numerosos no universo feminino brasileiro. ${ }^{6}$ Essa diferença havia sido destacada duas vezes também por Lara, uma das minhas interlocutoras de pesquisa, quando comentei que lá em Maputo as mulheres faziam penteados muito bonitos e ela respondeu que brasileiras se maquiavam muito.

Proponho considerar a cabeça como locus corporal privilegiado para investimentos estéticos entre as mulheres que convivi em Maputo, e os cabelos como adornos fundamentais para a construção de um corpo bonito. Os cabelos são adornos quando são objetos exógenos. Quando emergem da cabeça, são matéria-prima para tecelagem, suporte para aplicação de adornos, material passível de transformações químicas (Mercer, 2000). A eles é que se recorre para a realização de elaborações para enfeitar a cabeça, e é graças a eles que as mulheres ficam bonitas e possuem um corpo feminino. A cabeça é o suporte no qual investem-se elaborações visuais e desenham-se tramas; é para ela que o primeiro olhar das outras pessoas é direcionado. Pode-se pensar o corpo como um suporte para a arte sendo os cabelos a parte do corpo manipulável e material para esses investimentos. A forma de simbolizar os cabelos para essas mulheres é diferente daquelas que

6 Sobre a importância dos glúteos na estética corporal brasileira ver: Damatta (1991); Samarão (2008). Edmonds (2002) reflete sobre a importância do rosto no universo da cirurgia plástica entre mulheres do Rio de Janeiro, Brasil. O rosto, segundo seu campo revela, seria o cartão de visita das mulheres, o locus que revela a essência da pessoa. 
eu estava acostumada no Brasil. É a essa forma de simbolizar o corpo que me dedico na próxima sessão.

\section{Categorias que simbolizam esse corpo: cresce/não cresce; leve/pesado}

As mulheres que conheci simbolizam o corpo a partir de categorias opostas: de um lado haveria mulheres cujos cabelos não crescem, de outro mulheres que teriam cabelos que crescem. Visto que a cabeça é o suporte para empreendimentos estéticos e os cabelos, materiais para manipulação e desenvolvimento de formas, ter cabelos que crescem torna-se uma dimensão importante para essas mulheres. Aquelas que se pensam como tendo cabelos, ou cabelos que crescem, ressaltam esse atributo com orgulho.

Pode-se ter cabelos que crescem ou, simplesmente, ter cabelos, se, ao submetê-los a um processo químico chamado localmente de desfrisagem, eles fiquem ainda maiores. É também ter cabelos quando, puxados com as mãos, eles esticam-se $e$ crescem, tornando-se passíveis de intervenções como as tranças, por exemplo. Os cabelos entendidos como cabelos que não crescem seriam aqueles que, mesmo a partir do processo de desfrisagem, não aumentariam seu comprimento. Eles não se desenvolveriam a ponto de crescerem e, ao menos entre as pessoas que convivi, não se sabe explicar o motivo disso. Aquelas que se consideram com cabelos que não crescem apresentam uma relação de certa insatisfação com o corpo. Tal relação é ambígua, pois contém uma angústia que é transformada em formas, desenhos e apliques incríveis na cabeça para adorná-la.

Buscando entender qual cabelo era considerado feio e qual era considerado bonito, vi que não se tratava de qualidades $e$ julgamentos como "cabelo ruim" $e$ "cabelo bom", categorias encontradas no Brasil a respeito dos cabelos atribuídos à população reconhecida como "negra" ou "afro-descendente". Tampouco compartilhava-se da classificação "bad hair" e "good hair", encontrada nos Estados Unidos entre a população "afro- 
americana". ${ }^{7}$ Por outro lado, encontrei indicações de que elementos dessa perspectiva local, como o foco nos cabelos que crescem e o uso da expressão plantar cabelos para referir-se a algumas técnicas, podem ser encontrados em outros contextos africanos:

"Cabelo grande", "cabelo cheio", "muito cabelo" comunidades africanas ocidentais, incluindo os Mende, admiram uma bela cabeça com longos e grossos cabelos em uma mulher. Ambos estes elementos são cruciais: espessura e comprimento. A espessura é igual a aumento do número de fios individuais, o comprimento é a prova de força. Crescer um cabelo tão luxurioso requer paciência $e$ cuidado de uma mulher Mende. Uma vez que o cabelo de um homem é mantido raspado ou cortado junto ao couro cabeludo, as pessoas dizem que "os homens não têm cabelo". Cabelo bonito é, portanto, uma característica feminina; o mais feminino da mulher. ${ }^{8}$ (tradução nossa)

Essas categorias, embora aparentem servir como referentes de atributos inatos, são rapidamente emaranhadas devido à generalização do uso de técnicas que fazem os cabelos crescer. Mesmo aquelas que possuem cabelos que crescem lançam mão de adornos e de tratamentos químicos. Isso me levou a compreender que os cabelos, antes de qualquer coisa, são entendidos

7 Um belo trabalho a esse respeito sobre o contexto brasileiro é o da antropóloga Nilma Lino Gomes (2006). Asher (1995) reflete sobre a alteração capilar no contexto norte-americano. Ver também o filme: "Good hair", do apresentador de programas e comediante ChrisRock (2009), uma verdadeira etnografia do consumo de cabelos nos Estados Unidos.

8 “'Big hair', 'plenty of hair', 'much hair' - West African communities, including Mende $e^{8}$, admire a fine head of long, thick hair on a woman. Both these elements are crucial: thickness and length. Thickness equals increase in the number of individual strands, and the length is proof of strength. Growing such luxuriant hair requires a Mende womans patience and care. Because a man's hair is kept shaved or cut close to the scalp, people say that "men don't have hair". Beautiful hair thus is a distinctly female trait; the more of it, the more feminine the woman" (Boone, 1986:184). 
localmente como material para manipulação. Crescer ou não crescer diz menos de "atributos inatos" e mais das possibilidades de se elaborar arranjos na cabeça; o que está em jogo entre elas é o desejo disseminado de sempre produzir tais arranjos. A cabeça é a parte do corpo que recebe as maiores inovações estéticas e, pelo menos enquanto objetivo a ser alcançado, deve-se apresentar o máximo de penteados possíveis ao longo do tempo e renovar, assim, o corpo, bem como os elogios atribuídos a ele. Mulheres que têm cabelos que crescem e mulheres que têm cabelos que não crescem coadunam uma espécie de segredo publicamente compartilhado, visto que todas usam cabelos e adornos e alteram quimicamente seus fios.

O uso generalizado e indistinto dessas técnicas permite-nos expandir a ideia do segredo publicamente compartilhado: além de todas as mulheres usarem adornos e manipulações químicas, não é possivel saber quem tem cabelos que crescem e quem não os possui. Assim, o segredo de possuir ou não cabelos que crescem é um segredo que cada uma guarda para si. Compartilha-se também publicamente o conhecimento necessário para se fazer os penteados. Entre elas, basta um olhar sobre as cabeças alheias para que identifiquem quais foram as técnicas utilizadas para adorná-las; dimensão inalcançável aos que não sabem desse segredo. Tal cumplicidade diz respeito ao fato de que quase todas as mulheres sabem trançar e conhecem as técnicas de penteados.

Existem ainda duas outras categorias que classificam os cabelos dessas mulheres. Haveria, entre elas, aquelas que possuem cabelos pesados e aquelas que possuem cabelos leves, categorias que ouvi pela primeira vez a partir da fala de uma criança que saía da aula, na porta da escola.

Logo nos primeiros dias da minha estadia em Maputo, comecei a perguntar por salóes de beleza e por pessoas que trançassem. Mas as pessoas olhavam para mim e diziam: Trançar? Seus cabelos? Mas será que vão saber?

Eu não entendia porque não saberiam trançar meus cabelos $e$ ficava até um pouco impaciente com tais afirmativas. Foi quando, na porta de um colégio, conheci Flora e mais três 
meninas de tranças que olhavam para mim. Perguntei se elas sabiam trançar e elas me disseram que sim.

-Alguém pode me trançar? - indaguei.

- Mas o seu é difícil - responderam.

-Por quê?

-Porque seu cabelo é leve. - disseram enquanto friccionavam as pontas dos dedos para mostrar que meus cabelos eram leves e que escapariam de suas mãos. Flora, ao querer me dar a precisão da textura de meus cabelos, falava com o corpo e com as mãos. Parecia jogar-se junto com os dedos em uma tentativa de mostrar para mim que meus cabelos voavam e continuou a falar:

- Minha irmã tem os cabelos assim. [Puxou sua irmã e começou a acarinhar-lhe a cabeça] Ela até chora quando trança... Mas ela é corajosa.

Considerados difíceis de trançar, meus cabelos eram tão inapropriados que foram até desprezados por algumas cabeleireiras quando procurei seus serviços. Metáforas contrastantes como leveza e peso são muito recorrentes para a categorização dos cabelos entre as mulheres que convivi, embora não sejam definições rígidas para qualificar os cabelos. Cabelos pesados seriam aqueles que não crescem, que permanecem imóveis e não balançam a não ser depois de tratados quimicamente. Os cabelos leves, por sua vez, são os cabelos que voam, que o vento leva livremente, os que balançam depois de desfrisados, os que são comprados para aplicação das extensões e os cacheados, como os meus. Mais uma vez, os cabelos são simbolizados a partir de categorias que os qualificam quanto às possibilidades de se fazer coisas nele. O cabelo leve escapa das mãos, dói quando trançado, é difícil de ser manipulado. Os cabelos pesados podem ser submetidos a processos químicos para poderem transformar-se em material passível de alteração. Busquei revelar até agora como as mulheres simbolizam seus cabelos. Na próxima sessão buscarei deslindar um pouco do lugar 
que os cabelos usados na técnica chamada extensão ocupam em seus entendimentos.

\section{Cabelo: adorno-extensão}

O cabelo usado para trançar, seja qual for sua qualidade, apresenta uma ambiguidade sobre seu sentido e recebe atributos, funções e elementos distintos a depender de quem o usa, como usa e como as pessoas se relacionam com ele. Mizrahi (2010) descreve os cabelos usados na composição da estética corporal funk como extensões do corpo feminino. Para essa autora, o objeto cabelo mantém uma continuidade com o corpo daquelas mulheres fazendo-o um corpo mais suntuoso, confiante $e$ desejado. Ser um objeto-extensão significa dizer que cabelos não somente potencializam capacidades intrínsecas daquele corpo, mas apresentam caráter protético uma vez que concede a ele capacidades outras que não possui (Mizrahi, 2010:172). Buscarei deter-me aqui à maneira pela qual as mulheres que conheci relacionam-se com a aplicação dos cabelos buscando argumentar que, sejam eles quais forem - sintéticos, de verdade, humano - o uso das técnicas de embelezamento da cabeça apresentam o mesmo intuito: produzir matéria-prima suscetível a manipulações.

No momento da sua aquisição, os cabelos são entendidos por minhas interlocutoras enquanto adorno: inanimados $e$ fora de um corpo, eles seriam um material utilizado para adornar a cabeça. Funcionariam como um colar, um brinco ou uma pulseira e seriam escolhidos usando critérios de qualidade como um objeto sem vida. Acompanhei Pérola algumas vezes na compra de cabelos no Mercado Central. Ela os escolhia a partir de critérios como maciez, qualidade e versatilidade. Era preciso tateá-los para só então levá-los. Não apareciam preocupações sobre sua procedência, nem tampouco de quem deveriam ser aqueles cabelos; interessava somente se ficariam bem. ${ }^{9}$ Pérola ainda dizia

9 A falta de interesse da maioria das minhas interlocutoras por saber a procedência do produto, a meu ver, dava indícios sobre a desconfiança quanto a essa procedência. São muitos os rumores que giram em torno da origem dos 
que considerava o quanto os cabelos combinariam com seu rosto, e tinha vontade de sempre experimentar cabelos diferentes. Pessoas do meu convívio no Brasil estranharam essa relação com a compra de cabelos. O que mais lhes preocupava era saber de quem eles eram, mostrando uma dificuldade em pensar uma parte do corpo desligada do restante dele. $\mathrm{O}$ desinteresse pela procedência dos cabelos também está relacionado ao fato de que as mulheres com quem convivi estavam mais interessadas em fazê-los seus, anularem sua exterioridade através de uma mimetização entre fios da cabeça e fios aplicados. Incorporá-los e torná-los mais próprios era o desejo da maioria delas. O que se quer para esses objetos, depois de aplicados, é apagar as marcas da sua alteridade: fazê-los mais próprios é esconder essa exterioridade dos cabelos daqueles que irão admirá-lo. Os cabelos possuem essa ambiguidade de serem, simultaneamente, adornos e extensões do corpo, fundindo, em um só objeto, atributos de estética e beleza e atributos corporais.

Foram vários os comentários a ressaltar que, depois que se aplicam os cabelos, eles passam a ser da pessoa. Ou seja, para essas mulheres os cabelos passam a fazer parte do corpo daquelas que os aplicam. Depois de aplicado, ele transforma-se então em cabelo próprio, tendo implicações e exigindo cuidados bastante distintos de outros objetos, como colares ou pulseiras. No caso das extensões e tissagens, é preciso passar por um processo de familiarização e aprendizado sobre os cabelos aplicados. Eles atuam como um corpo externo que precisa ser domesticado $e$ tornado parte do próprio corpo. A esse respeito, é interessante

cabelos. Diz-se que são cabelos de pessoas que faleceram e que tiveram seus corpos desenterrados e seus cabelos cortados clandestinamente. Há também rumores de que exista um tráfico ilegal de cabelos. A desconfiança em torno deles não está desconectada da realidade, uma vez que participam de um mercado clandestino ainda pouco conhecido. $\mathrm{Na}$ Índia, lugar de onde vem grande parte desses produtos, os cabelos oferecidos em contexto ritual para entidades do sagrado são capturados e alocados clandestinamente no mercado (Rock, 2009). 
observar o que me disse Flávia sobre a primeira vez que colocou seus cabelos, utilizando a técnica chamada extensão:

Foi estranho. Ficou cheio e desorganizado. ${ }^{10}$ Aí a moça que colocou me explicou que aqueles cabelos cacheados, para baixarem o volume, tem que molhar e fazer assim [faz gestos com as mãos mostrando que se deve apertar um pouco os cabelos para dar forma]. E tem que colocar cremes de cabelos cacheados, que depois eu tive que comprar. Aí eu estranhei. Parecia outra pessoa. De repente, eu tinha aquele cabelo todo da noite para o dia. O Francisco [namorado] chegou em casa, viu e falou: "Flávia, o que é isso?"

Eu mostrei a surpresa. Ele gostou. Depois que eu coloquei aqueles cabelos, eu fiquei mais bonita. Todos diziam: "Você está bonita, Flávia!" É assim. Eu quero experimentar ter todos os cabelos. Cacheados, curtinhos, longos, lisos, iguais ao seu... Todos.

Em sua fala pode-se destacar: o estranhamento em relação àquele corpo exógeno; o aprendizado de como cuidar de um cabelo com o qual ela não estava acostumada; a necessidade de familiarização com os cabelos volumosos e cheios; a ambiguidade que os cabelos, enquanto adorno vivo, ensejam. Depois da sua aplicação na cabeça, eles passam a exigir cuidado permanente. É preciso agora cuidar deles com vitaminas, xampus específicos e tinturas. Ou seja, de objeto-adorno inanimado ele passa a ser incorporado, tendo que receber cuidados através de uma relação constante de manutenção e adequação dele ao corpo, ao rosto $e$ ao tom de pele daquela que o possui. Um dia, em uma conversa, Paula disse-me que os cabelos comprados e aplicados em extensões precisam de proteínas e vitaminas para continuarem bonitos e vivos:

${ }^{10}$ Termo utilizado que quer dizer: despenteado, desarrumado. Diz respeito à condição em que o cabelo se encontra e não a atributos inerentes a ele. 
Quando o cabelo está na cabeça, ele é alimentado por nosso corpo. Por exemplo, dizem que comer arroz faz o cabelo crescer e deixar ele forte. Mas se você tira o cabelo do corpo, ele continua a ser uma parte viva, e precisa de vitaminas e tudo que o corpo precisa.

A afirmação vinda de Paula e a descrição feita por Flávia sobre a primeira vez que aplicou extensões colocaram-me em contato com uma dimensão dos cabelos que extrapola sua atribuição como adorno: esses cabelos funcionam como uma espécie de adorno vivo, capaz de tornar-se parte de um corpo $e$ de demandar cuidados como se a ele pertencesse. Eles passam a ser, enfim, cabelos próprios.

\section{O sacrifício do corpo: dinheiro, tempo, resistência}

Investe-se-se muito dinheiro na compra desses adornos. Segundo o blog de Mutenda, os investimentos com os cabelos chegam a ultrapassar um terço dos salários de muitas mulheres de classe média. Mulheres que não têm muito dinheiro, afirma essa fonte, deixam de comprar roupas e outros itens da vestimenta para comprar esses acessórios. Em seu blog pessoal, uma moçambicana chamada Vanda publicou o seguinte texto:

Moçambicanas gastam até 17.000 meticais por vaidade.

A venda de "cabelo humano" vulgo extensões, em Moçambique virou moda, encontramos mulheres de todas idades, classes sociais com aquele tipo de cabelo. As moçambicanas preferem estar bem na cabeça e não ter "nada para vestir", isto é, gasta tanto dinheiro por colocar cabelo humano enquanto que por vezes dormi "debaixo da ponte". Mas só fazer os mais elevados sacrifícios pela vaidade. ${ }^{11}$

${ }^{11}$ [http://mulhermocambicana.com/2011/01/24/extensoes-capilares-uma-modaque-veio-para-ficar/] 
Interessante notar que a afirmativa de haver mais interesse nos cabelos que nas roupas é recorrente e reforça a afirmação de que a beleza está na cabeça. Roupas são, obviamente, elementos importantes na composição do corpo feminino entre as mulheres que convivi. Aquelas, no entanto, assumem um caráter secundário quando comparadas ao interesse em adornar a cabeça.

Outro investimento exigido para a aplicação dessas técnicas é o tempo e a resistência corporal. Tomados por essas mulheres como valores, a resistência à dor e o tempo empenhados para os penteados são enfatizados com orgulho por elas. Os penteados não levam menos que três horas para ficarem prontos $e$ havia quem gastasse seis, sete horas em salões, ou sentada esperando uma parente penteá-la. Tal atividade poderia começar no início do dia, depois do preparo do café-da-manhã, ter uma pausa no horário do almoço, prosseguindo depois que a louça estava limpa e continuando a ser feito no dia seguinte.No que se refere à dor como valor, Felícia revelou-me que muitas mulheres tomam remédios para dor e enrolam compressas de toalhas em volta da cabeça após trançarem os cabelos. "Trançar dói", repetiram-me várias vezes, e "para ser bonita é preciso ter dor". Vemos operar a esfera do sacrifício, na qual elementos como a dor, o tempo e o dinheiro despendidos para os investimentos estéticos são valorizados como necessários para se produzir beleza. Essa esfera não é exclusiva das mulheres moçambicanas, visto que há exemplos de sacrifícios correlatos nas mais diversas culturas, inclusive na nossa. Tampouco podemos considerar o ritual das tranças como uma espécie de longa sessão sacrificial: o momento de fazê-las é extremamente lúdico, geralmente acompanhado de música e conversas descontraídas sobre os mais variados assuntos.

Tanto trabalho investido na cabeça só poderia culminar, no final do processo, no estabelecimento de um verdadeiro tabu ao toque de terceiros. Uma vez que foram despendidos tempo, dinheiro e resistência corporal para a elaboração das tranças, quando prontas não podem mais ser tocadas nem pelos namorados, nem pelos amigos, nem pelos parentes, pois correm o risco de desfazer-se. 


\section{Corpos que se metamorfoseiam}

Paula, uma estudante da Universidade Eduardo Mondlane, de dezessete anos, deu-me fotos de todos os penteados que fez. $\mathrm{Na}$ seleção de imagens feita por ela há quarenta e quatro penteados, feitos ao longo de dois anos. Seus cabelos já foram compridos até a altura do busto, com mechas de cabelos loiros; foram trançados junto ao couro cabeludo com mechas loiras $e$ pretas; já estiveram desfrisados com os cabelos na altura dos ombros; foram trançados em mechas ruivas; costurados em tissagem de cabelos lisos na altura do queixo; penteados no estilo Jimi. $^{12}$

Não apenas Paula tem o hábito de registrar seus penteados. Outras mulheres que conheci, sobretudo as mais jovens, adotam essa prática. A cada novo penteado, as mulheres se portam como que renovadas e guardam expectativas de serem elogiadas por estarem com um visual completamente diferente. Sua postura corporal e feição mudam consideravelmente, e elas consideram-se "uma nova mulher" com os novos cabelos. Os cabelos, assim, acabam alterando gestos e performances e dando o norte sobre as roupas a colocar, e até a forma de se sentirem. Paula destacou ainda, em nossas conversas, que a mudança de cabelos implica em mudanças nas maneiras de sentir-se:

Quando eu quero parecer mais angelical eu coloco cabelos cacheadinhos. Quando eu quero parecer mais mulher eu coloco cabelos mais longos. Se quero parecer mais séria, mais formal, eu uso cabelos ondulados. O Jimi eu faço

\footnotetext{
$12 \mathrm{O}$ penteado conhecido internacionalmente como Afro surgiu nos Estados Unidos, no período de reivindicação dos direitos civis, sendo, desde então, o maior ícone de afirmação da beleza "afro-americana" (Mercer, 2000). Tal arranjo capilar se alastrou mundo afora, sendo também referência de resistência da população "afro-latina". Em Maputo, o penteado Afro recebe o nome de Jimi, em homenagem ao cantor norte-americano James Marshall "Jimi" (sic) Hendrix. Para as mulheres que conheci, trata-se de mais uma possibilidade de penteado estrangeiro no rol dos inúmeros possíveis.
} 
quando eu me sinto mais rebelde. Eu gosto de brincar com isso!

Alterar os penteados em um período curto de tempo estabelece com o corpo uma relação que é muito valorizada localmente. O desejo de mudar sempre é reforçado pelo valor, comum entre as jovens, de marcar a diferença. Marcar a diferença não é somente seguir os penteados, guiando-se pela moda: faz parte do entendimento de que é preciso inovar, surpreender com um novo penteado, estar à frente das novidades, criar complicações $^{13}$ na cabeça. Quando Paula comenta que, junto ao desejo de mudar, ela experimenta outras maneiras de ser, brinca com as possibilidades infinitas de tornar-se continuamente uma nova pessoa, a partir de novas performances. Vemos que, uma vez que os cabelos alteram o corpo dessas mulheres de maneira radical e constante, transformando-as em "outras mulheres" segundo suas próprias palavras, há uma relação com a estética da cabeça, na qual o efêmero é fundamental e valorizado. Aquela que pode sempre mudar seu penteado, atualizar-se, é tida como uma mulher de status e reconhecida por sua beleza. Seus corpos devem ser constantemente refabricados e reconstruídos, a fim de se tornarem femininos e belos.

Esse gosto pela constante mudança exige, naturalmente, um considerável estoque de cabelos disponíveis. É por isso que, entre as mulheres que conheci, uma prática de acúmulo de cabelos estava sendo cultivada. Idealmente, elas gostariam de ter todos os cabelos: curtos, longos, cacheados, ondulados, etc. $\mathrm{O}$ modo de armazená-los exige um conhecimento sobre sua conservação e é comum haver uma maleta ou baú para guardá-los. Não se guardam, além disso, os cabelos de qualquer maneira. Existe uma classificação para organizá-los: há os que são usados no dia-a-dia, pois, além de darem um ar mais casual, não demandam tanto tempo para aplicar e não são tão surpreendentes. Outros cabelos, reservados às festas, são guardados para serem acionados

\footnotetext{
${ }^{13}$ Ver adiante.
} 
somente em ocasiões solenes. Em geral, eles são mais suntuosos, maiores e inovadores. Há ainda as perucas que, menos comuns, são guardadas como possibilidades para serem acionadas no caso de um evento inesperado ou alguma emergência. Outra prática comum em relação aos cabelos é a sua troca entre amigas. Cabelos são objetos para presentear, comprando-se ou doando-se os próprios cabelos. A troca que pude observar se dava, em geral, entre mãe $e$ filha e entre amigas mais próximas, bem como entre irmãs. Cada vez que são retirados da cabeça, eles perdem um pouco dos fios e, consequentemente, do volume, tendo uma durabilidade restrita à sua aplicação e à circulação.

\section{Ornamentos e a entrada no universo das mulheres}

Os ornamentos podem representar diferenças entre idades (Seeger, 1980:51), podendo ser assim pensados em meu caso etnográfico. Desde muito cedo, as crianças entram em contato com os cuidados com a cabeça. Flora, filha de dois anos de Sandra, tinha seus cabelos trançados enquanto dormia, pois a menina reclamava que doía fazer as tranças enquanto estava acordada. Sua mãe a colocava delicadamente no colo e a trançava entre uma atividade doméstica e outra: buscar água, cozinhar, cuidar da casa. Amarrava em sua cabeça pequenos elásticos coloridos, separando mechas de cabelos e formando desenhos com riscos simétricos. Em outra casa, toda semana, sobretudo aos sábados, Lilô contava com sua mãe para fazer-lhe as tranças para que pudesse ir organizada para a aula. A empregada da casa, às vezes, se ocupava em ajudar a penteá-la, e sua irmã também contribuía. Por sua cabeça passavam várias mãos e os penteados poderiam demorar uma tarde inteira. Organizar é o termo que qualifica os cabelos penteados e bem cuidados, ao passo que seu antônimo desqualifica os cabelos despenteados. Não define a qualidade dos cabelos em si, mas a condição em que se encontram. Vivi, a pequena sobrinha da dona da casa em que eu morei, aparecia a cada semana com um penteado diferente. Eles alteravam consideravelmente sua feição, 
com elaborações que variavam desde tranças soltas $e$ rentes na nuca a elásticos coloridos e miçangas brancas.

Crianças podem ter em suas cabeças elásticos, miçangas $e$ adornos coloridos. A mudança constante de penteados e a alteração da feição são vivenciadas já no universo infantil, no qual as meninas aprendem a inovar constantemente nos penteados. Embora as meninas sejam introduzidas desde cedo nos cuidados com a cabeça, a entrada no universo das mulheres é marcada pelo uso de técnicas que são vetadas às primeiras. Os penteados das crianças não apresentam a mesma conotação de vaidade $e$ beleza que é referenciada somente às mulheres. Hoje, como aponta Felícia, somente as mechas feitas na altura do queixo são permitidas às crianças. Mesmo as mechas são entendidas como uma quebra de tabu que existia outrora. Trançar tissagem, aplicar extensões, desfrisar ou fazer escova não são permitidos às crianças.

A entrada no universo das técnicas mais sofisticadas equivale, assim, à entrada no universo das mulheres adultas. Em geral é a mãe que introduz a filha nessas práticas corporais. É ela quem oferece o primeiro cabelo e quem desfrisa o cabelo da filha pela primeira vez. Essa passagem é, portanto, ritualizada e expressa em corpos a partir de diferenças quanto o uso dos adornos. A partir de entrevistas realizadas com cinco mulheres, nas quais elas narravam suas histórias a partir das relações com as práticas corporais da beleza, foi possível observar que é por volta dos doze anos de idade, em geral, que uma menina é iniciada nas técnicas de desfrisagem, tissagem e extensão.

\section{Criação e criatividade}

A produção dos cabelos exige um conhecimento específico no qual as habilidades precisam ser aprimoradas, apresentando uma estética admirada. Tal atividade é reconhecida localmente como expressão artística: "As mulheres daqui fazem verdadeiras obras de arte nas cabeças das pessoas". As tranças simples, que envolvem mechas de cabelo divididas em três partes, 
entrecruzadas de forma intercalada, são aprendidas pela maioria das mulheres. Pérola disse-me que aprendeu a trançar-se sozinha quando ainda era pequena, pois seus cabelos, muito volumosos, ocupavam horas dos dias de sua avó. Aquelas que têm curiosidade aprendem a elaborar as complicações que as cabeças das mulheres mais exigentes demandam, sendo reconhecidas pelas demais. Elas apresentam uma narrativa em que afirmam terem tido curiosidade para aprender e aprimorar sua técnica. Curiosidade, aqui, é o termo local para aquilo que funciona como impulsionador do aprendizado das técnicas de pentear. Assim, estimuladas por essa curiosidade, muitas mulheres acabam trançando irmãs mais novas, amigas e vizinhas, expandindo sua fama de trançadeira e sofisticando sua técnica a partir da prática. Segundo apontam, é necessário persistir nas tranças, mesmo que no início elas não fiquem bem. Ser capaz de trançar bem, de fazer complicações nas cabeças das pessoas, era sempre algo mencionado como motivo de orgulho; não era raro que apontassem para a cabeça de alguma amiga e exclamassem: "Olha, fui que trancei ela", ou "Viu como ela está bonita? Fui eu que trancei a cabeça dela." Quando indagadas sobre esse processo criativo, elas me diziam:

Eu vou fazendo as tranças, aí eu penso, se eu puxar isso aqui para um lado vai ficar bonito. Se eu fizer para esse lado fica bem também. Se eu puxar uma para esse lado fica bonito. E assim vou fazendo essas complicações todas na cabeça. Vai ficando bonito.

Complicações é um termo usado para se referir a um valor estético. Ter complicações na cabeça é assumir o penteado mais sofisticado, aplicar os cabelos mais longos, ter os cabelos tornados mais próprios. As complicações são ainda tramas que confundem aquele que as vê, quanto à maneira como foram realizadas. Elas parecem querer confundir o observador, uma vez que não se pode acompanhar os caminhos que as tranças percorreram para criar-se aquele efeito visual. Ademais, compartilha-se uma espécie de ostentação na cabeça, seja a partir do uso de extensões bem 
longas, seja pela exibição das complicações. A cabeça precisa assumir relevância em relação ao restante do corpo, chamar atenção para si. Tramas simples, embora comuns, transmitem a ideia de pouca elaboração e, portanto, são menos apreciadas.

\section{Considerações finais}

Busquei, neste artigo, mostrar a centralidade que a cabeça possui para investimentos estéticos para algumas mulheres de Maputo. Os cabelos, por sua vez, são os adornos mais consumidos e desejados no universo da moda. O tempo, o dinheiro e a energia dispensados para a manipulação da aparência para essas mulheres se concentram no cuidado com os cabelos. Uma vez que os cabelos são a parte do corpo mais suscetível a manipulações, por ser maleável e alterável facilmente, essa é a parte do corpo cuja insatisfação pode ser manipulada. Os cuidados com o corpo não são levados sem conflitos $e$ angústias por parte dessas mulheres, que vivem um verdadeiro "preconceito capilar" (Malysse, 2002:14). Para elas, não ter cabelos ou ter cabelos que não crescem é um problema a ser solucionado depois dos onze anos de idade com os apliques e extensões. Podemos, além disso, afirmar que faz parte da cultura material da capital moçambicana, as técnicas e conhecimentos dedicados ao cabelo. Uma vez que elas envolvem elementos de criação e criatividade que são compartilhados pela maioria das mulheres da cidade.

\section{Referências bibliográficas}

ASHER, Bertram D. "Why don't he like my hair?": constructing africanamerican standards of beauty in Toni Morrison's songs os Solomon an Zora Neale Hurston's Their eyes were watching god. African American Review, 1995.

BOONE, Sylvia Ardyn. Radiance from the waters: ideals of feminine beauty in Mende Art. New Haven and London, Yale University Press, 1986. 
DAMATTA, Roberto. O que faz o brasil, Brasil? $5^{\mathrm{a} e d . ~ R i o ~ d e ~ J a n e i r o, ~}$ Editora Rocco, 1991.

EDMONDS, Alexander. No universo da beleza: notas de campo sobre cirurgia plástica no Rio de Janeiro. In: GOLDENBERG, M. (org.). Nu e Vestido, dez antropólogos revelam a cultura do corpo carioca. Rio de Janeiro, Record, 2002, pp.189/263.

GOMES, Nilma Lino. Corpo e cabelo como símbolos da identidade negra. Belo Horizonte, Autêntica, 2006.

GRANJO, Paulo. Saúde doença e cura em Moçambique. Instituto de Ciências Sociais - Universidade de Lisboa, 2005.

MALYSSE, S. R. "Extensões do feminino": megahair, banalidade e preconceito capilar. [www.studium.car.unicamp.br - acesso em 20 mar 2011].

MerCen, Kobena. Black Hair/Style Politics. In: OwUSU, K. (ed.). Representing Black Britain: Black and Asian Images on Television. British Culture and Society. London, Routledge/London, Croom Helm, 2000, pp.10/24.

MizRAHI, Mylene. A estética funk carioca: criação e conectividade em Mr. Catra. Rio de Janeiro, UFRJ, IFCS, 2010.

SAMARAO, Liliany. O espetáculo da publicidade a representação do corpo feminino na mídia. Contemporânea, no8, São Carlos, UFSCAR, dissertação, 2007.

SEEGER, Anthony. O significado dos ornamentos corporais. In: Os índios e nós - estudos sobre sociedades tribais brasileiras. Rio de Janeiro, Campus, 1980, pp.43-60.

VILARINHO, Sofia. Kikulacho kimo maungoni mwako: Kanga, da tradição à contemporaneidade.Buala, 2011. 